\title{
GEREFORMEERDE TEOLOGIESE OPLEIDING VIR AFRIKA IN DIE EEN-EN-TWINTIGSTE EEU
}

\author{
Koos van Rooy \\ Departement Ou Testament \\ Hammanskraalse Teologiese Skool \\ Potchefstroomse Universiteit vir $\mathrm{CHO}$
}

\begin{abstract}
Although the numbers and influence of the Reformed Churches in South Africa seem so bc dwindling at the moment, they still have a precious heritage which should be passed on to Africa: the reformed faith and reformed theology. Christianity is growing apace in Africa, but unfortunately this is often a superficial, nominal Christianity. A great need and desire for thorough, biblical, theological training does exist. This need should be answered by the Reformed Churches by providing theological courses for extension training at four academic levels, especially for equipping leaders of the independent African churches, not with the purpose of making proselites, but primarily with the purpose of biblical leaching where it is needed. These courses should be made available at inter alia the Polchefstroom University for Christian Higher Education, which is already involved in the Timoteus correspondence course.
\end{abstract}

Hoewel gereformeerde teologiese opleiding gelukkig nie beperk is tot die Gereformeerde Kerke in Suid-Afrika nie, is die fokus van hierdie artikel hoofsaaklik gerig op die opleiding deur genoemde kerke. Verder is dit geskryf met hoofsaaklik die behoeftes van die swart Christene in gedagte.

\section{DIE SUBJEK VAN DIE OPLEIDING}

Hier sal gevra moet word wat die vermoëns van die Gereformeerde Kerke is. Eerstens behoort die vermoëns getalsgewys bestudeer te word en in hierdie opsig lyk die prentjie nie baie gunstig nie. 'n Studie van die betrokke kerkalmanakke bring aan die lig dat onder stedelike swartmense die getalle van lidmate van die Gereformeerde Kerke die afgelope vyftien jaar aan die krimp is. Die huidige tempo van verstedeliking van Swartmense (Kritzinger, 1988:84-93) dui daarop dat die toekoms van die kerk in Afrika in die stede gesoek moet word. 'n Kerk wat nie in die stad staande kan bly nie, gaan uitsterf.

Wat die blankes betref, dui statistieke duidelik daarop dat die Gereformeerde Kerke 'n sterwende kerkefamilie is. Gedurende die afgelope drie jaar toon die getalle van blanke lidmate 'n steeds vinniger afname. Die afname in die getalle van die totale 
lidmatetal, dooplidmate ingesluit, was in 1986/87 ongeveer 500 , in $1987 / 88$ ongeveer 800 ,en in 1988/89 ongeveer 1000. (Almanak van die Gereformeerde Kerke in SuidAfrika, 1988, 1989, 1990).

Die oorsake hiervoor moet nie by die gereformeerde belydenis gesoek word nie, en ook nie by die gereformeerde teologie nie - dit is 'n ryk en kosbare erfenis, wat slegs tot groot nadeel van die kerke en van die evangelie in Afrika oorboord gegooi kan word. Die grootste herlewings in die geskiedenis van die kerk het juis in kerke met 'n Calvinistiese belydenis en deur die prediking van die basiese gereformeerde waarhede plaasgevind (Lloyd-Jones, 1987:1-23).

Solank daar nog Gereformeerde Kerke in Afrika is, hoe klein ook al in getalle, het daardie kerke dus 'n hoë roeping, naamlik om met hulle talent te woeker. Vervolgens word dan omlyn wat hierdie talent is.

\section{DIE INHOUD VAN DIE OPLEIDING}

Die inhoud sluit die Bybelse, Calvinistiese leer en teologie in. Die gereformeerde teologie is die enigste teologie wat werklik met die Bybel ooreenstem. Dit is ook die enigste teologie wat aan God die eer gee wat Hom toekom omdat dit sy uitgangspunt neem in God se soewereiniteit. Daar is 'n lang tradisie van deeglike eksegetiese en leerstellige teologiese opleiding onder Gereformeerdes, waarmee saamhang 'n redelik intensiewe opleiding in die klassieke tale waarin die Bybel geskryf is. By geen ander teologiese tradisie word dit geëwenaar nie. By al die gebreke in teologiese opleiding deur die Gereformeerde Kerke, kan 'n mens tog die gunstige effek van hierdie deeglike teologiese opleiding sien. So is daar byvoorbeeld by swart teoloë van hierdie kerke nog min indien enige tekens van simpatie vir die Bevrydingsteologie, selfs in die vorm van Swart Teologie. Sinodebesluite dra nog sterk die stempel van 'n konfessionele Skrifgebondenheid.

Al sou die Gereformeerde Kerke onder blankes dan uiteindelik moet uitsterf, wil 'n mens die hoop uitspreek dat hulle ten minste hierdie kosbare erfenis as 'n nalatenskap vir Afrika sal agterlaat. Daar rus op hulle die verpligting om dit so wyd as moontlik uit te dra.

\section{DIE OPSET VAN DIE OPLEIDING}

Op die oomblik is die opleiding hoofsaaklik op die eie behoeftes van die kerke gerig. Die opleidingsinrigtings slaag daarin om ongeveer genoeg kandidate te lewer vir die 
aantal vakatures wat daar is, en let wel nie "om in die behoeftes te voorsien" nie. Die feitelike situasie is dat die behoeftes meer is as die vakatures, maar omdat die traktement van swart predikante in baie gevalle nog hoofsaaklik deur blankes voorsien word, is daar nie genoeg fondse om in al die behoeftes te voorsien nie.

Die praktyk is dan dat jong, onbeproefde manne as studente aanvaar word - studente an wie hoofsaaklik akademiese voorvereistes gestel word. Die vereistes wat die Skrif stel in 1 Timoteus 3:1-7 en in Titus 1 (" ... getrou aan sy vrou, gasvry, bekwaam om te onderrig, goeie beheer oor sy eie gesin, geen nuweling nie") figureer nie sterk nie. Trouens, hoe kan dit figureer in die geval van 'n ongetroude, onervare jongman? In die Skrif daarenteen word akademiese vaardigheid en hoè intelligensie nie eers genoem nie.

Hierdie opset is onder blankes nog redelik geslaagd, omdat dit normaalweg vir 'n jong blanke man 'n groot opoffering is om predikant te word, en dit dus nie maklik gebeur dat iemand wat nie werklik geroepe is, of wat geen genadegawes vir die bediening het, wel tot die bediening toegelaat word nie. By swartmense is dit egter anders. Vir baie van hulle is toelating tot die Hammanskraalse Teologiese Skool'n welkome geleentheid om sonder veel opoffering akademiese kwalifikasies te verwerf. Hierdie swart jongmanne word dan vir minstens sewe jaar uit hulle natuurlike milieu weggeneem en aan 'n massa teologie blootgestel. As hulle goeie begrip en veral geheue het, en die stof wat hulle leer, goed kan weergee, behaal hulle goeie punte in die eksamen.

Hulle doen gedurende naweke praktiese werk, maar die waarde daarvan word beperk deur die feit dat hulle min begeleiding daarvoor kry. As hulle aan die einde van hulle studie goeie akademiese resultate toon, word hulle feitlik outomaties predikante - asof mense predikante kan maak!

Dit bly ' $n$ vraag of die genoemde stelsel en opleiding werklik sinvol is. Tog gebeur dit dat van die oud-studente soms predikante word wat met seën in gemeentes en as sendelinge werk. Daar is dus tog van hulle wat werklik deur God geroep is en met die gawes van die Gees toegerus is.

Tog is die resultate alles behalwe bevredigend. Die registrateur van die Hammanskraalse Teologiese Skool het bereken dat daar by geleentheid 40 studente ingeskryf was, van wie op die ou end nouliks vyf predikante geword het. In die lig hiervan kan die vraag sekerlik gevra word of dit nie neerkom op verkwisting van fondse wat vir die diens van die Here en die evangelie bygedra is nie.

Bowendien word 'n groot deel van die predikante spoedig na voltooiing van bulle studie afgesit, of verlaat hul die bediening om ' $n$ ander werk te aanvaar. 'n Mens hoef 
maar net in die betrokke almanakke te kyk na die lang lys van "predikante wat 'n tyd lank in diens was".

Hierdie stelsel werk redelik goed in 'n "middelklas denominasie" soos die Gereformeerde Kerke onder die blankes. Onder die swartmense is daar egter nog maar 'n baie klein middelklas, en daardie middelklas bevat baie min Gereformeerdes. Tog kan 'n mens die swart predikante wat dieselfde opleiding as blankes het, nie kwalik neem dat hulle darem 'n vergelykbare "middelklas"-traktement verwag nie. Verskeie van die mees begaafdes het dan ook al die bediening verlaat om ander werk te soek, of het 'n ander werk wat beter betaal as "tentmakersverdienste" benewens hulle predikantswerk aanvaar.

Hoe moet 'n mens verwag dat 'n kerk wat grotendeels uit behoeftiges bestaan, van wie baie selfs onder die broodlyn lewe (Kritzinger, 1988:56-67), nou 'n predikant met 'n middelklastraktement moet versorg? Dit klop eenvoudig nie. Die huidige stelsel is niks anders nie as Dawid in Saul se harnas: solank hy daarmee rondloop, is Goliat veilig! Die bedieningspatroon van swart kerke is grotendeels 'n kunsmatige konstruksie wat tot in die verre toekoms met sustentasie van buite aan die gang gehou sal moet word. Nou is dit heeltemal Bybels dat kerke mekaar in hulle nood help - hierdie beginsel was trouens die aanleiding vir Paulus se tweede brief aan die Korintiërs (2 Kor. 9). Wanneer hierdie hulp egter 'n vaste patroon word met geen vooruitsig dat die naelstring ooit afgesny sal kan word nie, is daar iets radikaals verkeerd. 'n Bediening wat alleen kan bestaan by die grasie van finansiële hulp van buite, is nie meer ' $n$ lewensvatbare bediening nie. Die kerk wat daardeur aan die lewe gehou moet word, is nie meer 'n lewensvatbare kerk nie, maar 'n kunsmatige konstruksie (vgl. ook Kritzinger, 1977:40).

Persoonlik is ek op grond van die volgende argumente oortuig dat dit sonde is om op hierdie manier aan te gaan.

- Dit laat die bediening van herder en leraar op baie plekke ontaard tot dié van sakramentsreisiger, wat soms slegs eenkeer in maande by elke pos kan uitkom.

- Dit ontneem die plaaslike gemeentetjies (buiteposte), die plek waar die kerk werklik leef en as liggaam van Christus moet funksioneer, die toegang tot gereelde Woord-en sakramentsbediening.

- Die ergste van alles is dat dit baie gou werklike sendingwerk en die uitbreiding daarvan onmoontlik maak, omdat sogenaamde "sendinggelde" wegsink in die bodemlose put van sustentasie aan bestaande gemeentes. Intussen wag die drie biljoen onbereikte mense op die evangelie, en Gereformeerdes kan hulle nie meer bereik nie. Net die Onafhanklike Kerke en die Pinksterkerke kan nog werklik uitbrei, omdat hulle 'n lewensvatbare bedieningspatroon gevind het (Kritzinger, 
1979:88). Die Assemblies of God se lidmatetal in Latyns-Amerika beloop na skatting nou reeds tien miljoen (Anon, 1990:6).

\section{Gee vir Dawid sy slingervel terug!}

Ek is oortuig dat daar geen ander alternatief is nie as dat in veel groter mate van ' $n$ tentmakersbediening gebruik gemaak moet word. Ek is daarvan bewus dat dit ook baie probleme meebring, maar dit is ten minste 'n lewensvatbare, organiese, natuurlike (in die Bybelse sin) bedieningspatroon. Dit werk, en kerke wat dit toepas, groei. Trouens, in Afrika en Latyns-Amerika is dit die enigste kerke wat werklik nog groei. Dit is in 'n groot mate aan hulle te danke dat Afrika nou reeds nominaal die mees gekerstende kontinent op aarde is (Barret, 1989:20-21).

Met die woord nominaal is egter 'n groot uitdaging aangedui, en hierby wil ek nou verder aansluit. Die Christendom in Afrika dreig om homself dood te groei (Adeyemo, 1984:27-29). Daar is 'n skreiende gebrek aan teologiese kennis en opleiding. Ek meen dat dit in ooreenstemming met die Gereformeerdes se "een talent" is om 'n bydrae te lewer om in hierdie ontsaglike nood te help voorsien. Daar is reeds die eerste tree op hierdie weg geplaas toe studente uit Zaire by Hammanskraal aanvaar is, en daar is die vooruitsig van baie meer. Dit mag moontlik die grootste roeping van die Gereformeerde Kerke blyk te wees - om hulle vleuels veel wyer uit te slaan.

Daar is in Afrika 'n honger na teologiese opleiding, 'n feit wat gestaaf word deur die groot getalle studente wat by UNISA vir Bybelkunde en teologie inskryf - die fakulteit Bybelkunde en Teologie van UNISA is waarskynlik die grootste in die wêreld. Omdat kerklike en konfessionele binding egter ontbreek, verskil die fokus van die teologiese opleiding aan UNISA grootliks van dié wat van 'n Gereformeerde predikant vereis word.

Hierdie feite plaas op Gereformeerdes 'n groot verantwoordelikheid. By al die sondes en gebreke van Gereformeerdes is daar tog nog by hulle die wil om aan die gereformeerde, Bybelse leer vas te hou. Vrysinnigheid was tot dusver nog nie geassosieer met die Gereformeerde Kerke nie.

\subsection{Enkele konkrete aanbevelings}

\subsubsection{Die oopstel van bestaande fasiliteite}

Daar het reeds studente uit Korea en elders met groot vrug aan die PU vir CHO studeer. Ook is daar verskeie aansoeke van studente uit Zaïre ontvang om by 
Hammanskraal te studeer. Dit is 'n stap in die regte rigting.

Wanneer gepleit word vir 'n meer organiese bedieningspatroon, beteken dit nie dat die stelsel van voltydse teologiese opleiding en voltydse predikante oorboord gegooi moet word nie - daar is nog steeds ruimte daarvoor en behoefte daaraan. Die kerke van Afrika het ook grondig opgeleide teoloë nodig, en dit sal hoofsaaklik voltydse opleiding van voltydse teoloë wees wat in daardie behoefte sal kan voorsien.

Een verandering wat in hierdie stelsel aangebring sal moet word, is dat professore minder formele lesings behoort te gee en meer tyd vir selfstudie van studente moet inruim. Hierdie selfstudie kan dan in gereelde besprekingseminare in plaas van formele lesings gekontroleer en begelei word. Uit die persoonlike reaksies van oudstudente kan afgelei word dat dit vir hulle veel meer werd sal wees as formele lesings. Dit sal die professore ook in staat stel om hulle tyd meer produktief te gebruik - en as wat hierin aanbeveel word, aanvaar word, sal dit baie nodig wees! Onder andere kan hulle beter lesings en studiegidse uitwerk om die studente met hulle selfstudie te help.

Nog 'n belangrike verandering is dat die opleiding op Hammanskraal na Engels as medium van onderrig moet oorskakel. Die doel van die Hammanskraalse Teologiese Skool is nie om die Afrikaanse taal en kultuur te bevorder nie, maar om met die mense van Afrika te kommunikeer en die gereformeerde teologie vir hulle as erfenis na te laat. Hiervoor is daar net een aangewese medium buiten die Bantoetale, en dit is Engels. (Daar word aangeneem dat daar nog nie die middele is om kursusse ook in Portugees en Frans aan te bied nie, laat staan nog Swahili en Arabies!)

Een verdere wysiging in die bestaande patroon van ons voltydse opleiding sou wees dat daar meer aandag aan praktiese opleiding gegee sal moet word. In hierdie opsig behoort die voorstel wat ds. Chris Coetzee by die opfrissingskursus gedurende Januarie 1990 te Hammanskraal gemaak het, van harte ondersteun te word. Dié voorstel behels dat aan elke professor 'n woongebied toegewys moet word wat hy saam met 'n aantal studente moet bearbei om hulle alle aspekte van die opleiding prakties te leer toepas, sendingwerk inkluis.

\subsubsection{TEE (buitemuurse opleiding)}

Daar is reeds daarop gewys dat die oorgrote meerderheid van predikante van kerke (wat nog groei), tentmakerpredikante is. Hulle onderhou hulleself uit 'n beroep of deeltydse beroep, en saans en gedurende naweke bedien hulle gemeentes. Natuurlik kan so 'n predikant nie 'n groot gemeente bedien nie, maar hy kan wel, as hy die gawes 
van die Gees het, 'n klein gemeentetjie baie intensief bedien. Dit maak ook klein gemeentetjies in yl bevolkte gebiede organies lewensvatbaar.

Dit het uit ervaring in Latyns-Amerika geblyk dat dit moontlik is om aan "tentmakers" ook 'n behoorlike teologiese opleiding te gee. Studies soos dié van Ralph Winter (1969) en Kenneth Mulholland (1976) het dit oortuigend aangetoon. Op hierdie aspek word later ingegaan.

Aangesien daar by hierdie groep mense 'n groot verskil in akademiese standaard, intelligensie en Bybelkennis is, behoort die kursusse op minstens drie vlakke aangebied te word, maar verkieslik vier.

In die eerste plek, soos reeds genoem is, moet dié wat daartoe in staat is, by bestaande voltydse opleiding ingeskakel word, maar dan met die wysigings en beleid soos hierbo bepleit.

Om tot TEE terug te keer: daar behoort op minstens drie vlakke hiervoor voorsiening gemaak te word. Eerstens dan meer besonderhede oor TEE (Theological Education by Extension) (vgl. vir meer besonderhede Mulholland, 1976:55-73 en Winter, 1969:261-374); hierdie stelsel word dan ondersoek deur dit te vergelyk met ander, verwante onderrigstelsels.

\section{Korrespondensiekursusse}

Hierdie stelsel het sy voordele, wat veral daarin lê dat 'n bykans onbeperkte studentetal bereik kan word. UNISA is ' $n$ skitterende suksesverhaal van korrespondensieopleiding. Dit het egter ook verskeie nadele.

- Terugvoering kan lank vertraag word, met die gevolg dat verkeerde persepsies kans kry om te bly vassteek.

- Dit vereis 'n baie hoë vlak van motivering, wat blyk uit die hoë persentasie studente wat tou opgooi.

- Om van waarde te wees, moet lesings baie eksplisiet wees. Om dit gedurig op datum te hou, is duur.

- Omdat daar min kontak tussen dosente en studente is, is dit moeilik om die opleiding altyd ter sake te hou. Die werklike behoeftes van studente word nie altyd aangespreek nie.

Korrespondensiekursusse kan wel met vrug gebruik word vir addisionele onderrig nadat die basicse kursusse afgehandel is en die studente reeds die tegniek van studie 
bemeester het.

\section{Kort kursusse}

Hiermee word kursusse van drie of vier maande bedoel, kursusse waarin soveel materiaal as moontlik afgehandel word. Die voordeel hiervan is dat die student nie van sy milieu vervreem word nie, en dat daar, anders as by korrespondensieopleiding, wel persoonlike kontak tussen dosent en student is.

Die nadele is die lae akademiese standaard wat noodwendig gehandhaaf kan word, en die feit dat min persone selfs vir drie maande hulle werk kan los.

\section{Aandskole}

Die sukses van aandskole lê daarin dat mense dit in hul vrye tyd bywoon en dat daar gewoonlik ' $n$ atmosfeer van gelowige toewyding heers. Dit is egter meer geskik vir die toerusting van lidmate, aangesien dosente van TEE nie daagliks studente kan besoek nie.

\section{Vakleerlingskap}

Vakleerlingskap was die stelsel wat Paulus hoofsaaklik gebruik het en wat ook teenswoordig met geweldige sukses deur die Pinksterkerke in Latyns-Amerika gebruik word. Die voordele hiervan word vervat in die voorstel dat professore saam met studente in ' $n$ woongebied werk. Die voordele van vakleerlingskap as opleidingsmetode is velerlei:

- Dit is Bybels; dit is die metode wat die apostels gebruik het (Floor, s.j.:45-50).

- $\quad$ Dit bied 'n dinamiese, organiese, praktiese vorm van bediening en opleiding.

- Kandidate word nie deur die seminarie opgelei nie maar deur die straat; hulle is dus tuis in die straat en in die krotbuurtes - anders as die skoolse opleiding wat studente hoofsaaklik vir'n middestandsbediening voorberei.

- Elke bekeerling word dadelik ' $n$ evangelis

Die nadele is die volgende:

- Hierdie soort opleiding berus baie sterk op tradisie.

- Die persoon van die pastor word die model en dus ook die plafon wat die student kan bereik. 
- As gevolg van gebrek aan teologiese kennis dra die opleiding dikwels 'n sterk pragmatiese karakter.

- Verkeerde gebruike word onkrities nagevolg.

TEE skakel die nadele van al hierdie stelsels uit, maar behou die voordele daarvan. TEE beteken eenvoudig dat die seminarie uitgebrei word, na die student geneem word, en dan wel na reeds beproefde kerkleiers, wat blyke gegee het dat hulle die charismata besit wat die Bybel vereis. Dit moet weer eens benadruk word dat TEE nie ' $n$ minderwaardige opleiding beteken nie, maar dat dit wat die standaard betref met die beste voltydse opleiding vergebyk kan word (Winter, 1969:411).

Daar is drie kardinale elemente wat eie is aan TEE.

- Weeklikse besprekings van materiaal deur die dosente en studente. Dit begin elke week met ' $n$ kort toets om die dosent 'n aanduiding te gee van wat die student sy eie gemaak het. Daar is geen formele lesings nie en geen papegaai-memorisering van werk nie. Daar is werklik geestelike gemeenskap tussen dosent en student.

- Selfstudiemateriaal, wat egter nie korrespondensie-opleiding is nie. Die materiaal bevat weeklikse studie-opdragte op verskillende vlakke vir studente van verskillende akademiese vlakke. Die positiewe aspek van hierdie metode is dat aldrie vlakke dieselfde klasse bywoon, want dit is nie formele lesings nie; dit is slegs besprekings van probleme. Ervaring het bewys dat die verskillende groepe bevrugtend op mekaar inwerk. Dié van 'n hoër akademiese vlak leer om hulle probleme in eenvoudige taal en op konkrete wyse te stel. Die minder ontwikkelde studente word deur die meer gevorderdes geleer om abstrakte begrippe te begryp en te hanteer en om krities te dink. Elke student vorder teen sy eie pas.

- Driemaandelikse sentrale saamtrekke. Hierdie element van die onderrig is nodig vir die onderlinge motivering van studente en vir geestelike gemeenskap en onderlinge verryking en bespreking van gemeenskaplike probleme.

TEE het ' $n$ besliste voordeel bo die huidige stelsel van opleiding deurdat dit hoofsaaklik ryper, beproefde manne trek en nie die jong manne wat so dikwels teleurstel nie. Gekombineer met vakleerlingopleiding, skakel dit die nadele daarvan uit en behou die voordele.

Hierdie vorm van opleiding is ongelukkig minder geskik as metode om aanvangskursusse in klassieke tale aan te bied vir studente wat nie besonder begaaf is nie. Meer gevorderde kursusse, soos Grieks 3 en Hebreeus 3, kan egter baie goed hierdeur aangebied word, aangesien die student dan reeds die basiese kennis van die taal 
verwerf en self leer studeer het.

Dit moet egter beklemtoon word dat daar wel die voltydse studente sal wees wat 'n behoorlike kennis van die klassieke tale sal verwerf, maar daar is van die ouer swart predikante wat geen klassieke tale geleer het nie, en nogtans beter eksegete is as sommige van hulle kollegas wat dit wel geleer het. Baie van dié wat wel klassieke tale bestudeer het, het soveel daarvan vergeet dat hulle vir alle praktiese doeleindes funksioneel ongeletterd in die klassieke tale is. Ek wil dit in die lig hiervan stel dat goeie kennis van Grieks en Hebreeus wenslik is om verantwoorde eksegese te doen, maar nie absoluut essensieel is nie. Waar daardie kennis wel van die student vereis word, moet die kennis daarvan egter voldoende wees om sinvol met die tale te kan omgaan. Normaalweg is Grieks 2 en Hebreeus 2 myns insiens nie naastenby voldoende nie.

Daar behoort dus ' $n$ kursus aangebied te word wat in alle opsigte die standaard van die huidige voltydse kursus handhaaf, behalwe dat toegewings gemaak kan word wat betref kennis van die klassieke tale en veral Hebreeus.

As alternatief behoort ook ' $n$ kursus aangebied te word, wat B.A. (Teologie) of B. Theol. genoem word, wat al die teologiese vakke van die voltydse kursus bevat, maar in minder detail daarop ingaan. Hierdie kursus behoort in ses tot agt jaar se deeltydse studie afgehandel te kan word.

Die derde alternatief is dan 'n universiteitsdiploma in teologie, wat die voorstel hierbo genoem nog ietwat kondenseer, en bedoel is vir mense wat nie matriekulasievrystelling het nie. As dit vir die universiteit onmoontlik is om hierdie diploma in sy programme in te skakel, moet die Hammanskraalse Teologiese Skool dit self aanbied.

Die vierde alternatief, waarvoor slegs 'n leeskennis van Engels vereis behoort te word, kan 'n tweejarige diploma in basiese Teologie en Diakoniologie wees - 'n kursus wat baie eenvoudig en onakademies moet wees, en slegs die vakke Openbaringsgeskiedenis, Tegniek van eksegese (van die teks na die preek), Apologetiek (beperk tot die godsdienste van Afrika), Etiek, Christelike Leerstellings, en Pastorale Teologie (hoe om te evangeliseer, 'n gemeente te organiseer, 'n katkisasieklas in te rig, 'n pastorale besoek te benader) moet insluit.

Addisionele kursusse kan opgeneem word, maar moet nie 'n vereiste vir hierdie basiese diploma wees nie. Natuurlik sal die universiteit hierdie groep nie kan akkommodeer nie, maar dit sal goed wees as hulle op 'n "onoffisiële rol" kan kom. 


\section{OPMERKINGS EN IMPLIKASIES}

Dit is belangrik dat die betrokkenheid van die PU vir $\mathrm{CHO}$ so gou as moontlik vasgelê word. Daar is beslis belangstelling, en die Departement Bybelkunde het reeds die Timoteus-korrespondensiekursus onder sy vlerke geneem. Hierde kursus het duisende studente en dit bied ' $n$ belangrike aanknopingspunt.

Dit is egter essensieel dat die PU vir CHO so gou moontlik 'n korrespondensiekursus in Bybelkunde en Teologie aanbied. Van hierdie kursusinhoud kan ook by die TEEkursus gebruik word.

Vir die TEE-kursus kan die PU vir CHO dan van die personeel van die Hammanskraalse Teologiese Skool gebruik maak. Die opleiding moet steeds onder toesig van die kuratore geskied, maar dit moet in die naam van die PU vir $\mathrm{CHO}$ aangebied word, want vir die meeste leraars van Onafhanklike Kerke sal 'n kerklike opleiding onaanvaarbaar wees, terwyl die universiteit ' $n$ neutrale beeld het en bowendien status aan die kursus verleen.

- Bestaande opleidingsentra soos die in Potchefstroom, Vereeniging, Venda, Natal en Bophuthatswana, selfs Dimbaza, kan by hierdie opleiding ingeskakel word. Sendelinge en predikante kan help met die seminare (geen formele lesings nie!)

- Die TEE-kursus kan strek oor soveel jare as wat dit elke individuele student neem om die kursus te voltooi. Sommige sal dit in agt jaar kan voltooi, sommige miskien in sestien, maar intussen is daardie manne vrugbaar besig om hulle verworwe kennis in diens van die gemeente toe te pas.

\section{SLOTSOM}

lemand wat aan teologiese arthritis ly, gaan die veranderinge hierin voorgestel baie pynlik vind. Ter wille van die koninkryk van God en ons taak daarin is dit egter noodsaaklik dat ons soepel genoeg is om die opset van ons opleiding aan die Skrif te toets en by die behoeftes van Afrika aan te pas.

\section{BIBIJOGRAFIE}

ADEYEMO, T. 1984. The Church in Africa Today. Orientation, 32:22-59.

BARRETT, D.B. 1989. Annual Statistical Table of Global Mission. Intemational Bulletin of Missionary Research, 13(1):20-21, Jan.

FLOOR, L. s.j. In dieselfde spore. 'n Ondersoek na die struktuur van die sendingwerk. Potchefstroom : Dic Evangelis. 96p. 
HILL, B.N. 1988. The Fall and the Rise of TEE in one African Church. Evangelical Missions Quanerty, 24(1), Jan: $42-47$.

KRITZINGER, JJ. 1979. 'n Missionére bediening - op weg na strukture vir 'n jong kerk. Pretoria : NG Kerkboekhandel. 231 p.

KRITZINGER, J J. 1988. Die onvoltooide sendingtaak in Suid-Afrika. Pretoria : ISWEN. 116p.

LLOYD-JONES, D.M. 1987. The Puritans: Their Origins and Successors. Edinburgh : Banner of truth, p. 1-23.

MUlHOLlAND, K.B. 1976. Adventures in Training the Ministry. Phillipsburg : Presbyterian and Reformed Publishing Co. 219p.

ANON, 1990. RE.C. News Exchange. : 6, Feb.

WINTER, R.D. (Ed) 1969. Theological Education by Extension. Pasadena : Wm. Carey Library. 589 p. 